\title{
Gene methylation biomarkers in sputum as a classifier for lung cancer risk
}

\author{
Shuguang Leng ${ }^{1}$, Guodong $\mathbf{W u}^{1}$, Donna M. Klinge ${ }^{1}$, Cynthia L. Thomas ${ }^{1}$, Elia \\ Casas $^{1}$, Maria A. Picchi ${ }^{1}$, Christine A. Stidley ${ }^{2}$, Sandra J. Lee $^{3}$, Seena Aisner ${ }^{4}$, Jill \\ M. Siegfried ${ }^{5}$, Suresh Ramalingam ${ }^{6}$, Fadlo R. Khuri ${ }^{6}$, Daniel D. Karp ${ }^{7}$ and Steven \\ A. Belinsky ${ }^{1}$ \\ ${ }^{1}$ Lung Cancer Program, Lovelace Respiratory Research Institute, Albuquerque, NM, USA \\ ${ }^{2}$ Department of Internal Medicine, University of New Mexico, Albuquerque, NM, USA \\ ${ }^{3}$ Dana-Farber Cancer Institute, Harvard Medical School, Boston, MA, USA \\ ${ }^{4}$ Rutgers New Jersey Medical School, Newark, NJ, USA \\ ${ }^{5}$ Department of Pharmacology, University of Minnesota, Minneapolis, MN, USA \\ ${ }^{6}$ Department of Hematology and Medical Oncology, Winship Cancer Institute of Emory University, Atlanta, GA, USA \\ ${ }^{7}$ MD Anderson Cancer Center, Houston, TX, USA \\ Correspondence to: Steven A. Belinsky, email: sbelinsk@LRRI.org \\ Keywords: gene methylation, lung cancer risk, biomarker, CT screening \\ Received: March 14, $2017 \quad$ Accepted: June 05, $2017 \quad$ Published: July 15, 2017 \\ Copyright: Leng et al. This is an open-access article distributed under the terms of the Creative Commons Attribution License 3.0 \\ (CC BY 3.0), which permits unrestricted use, distribution, and reproduction in any medium, provided the original author and source \\ are credited.
}

\section{ABSTRACT}

CT screening for lung cancer reduces mortality, but will cost Medicare 2 billion dollars due in part to high false positive rates. Molecular biomarkers could augment current risk stratification used to select smokers for screening. Gene methylation in sputum reflects lung field cancerization that remains in lung cancer patients postresection. This population was used in conjunction with cancer-free smokers to evaluate classification accuracy of a validated eight-gene methylation panel in sputum for cancer risk. Sputum from resected lung cancer patients $(\mathbf{n = 4 8 7 )}$ and smokers from Lovelace $(n=1380)$ and PLuSS $(n=718)$ cohorts was studied for methylation of an 8-gene panel. Area under a receiver operating characteristic curve was calculated to assess the prediction performance in logistic regressions with different sets of variables. The prevalence for methylation of all genes was significantly increased in the ECOG-ACRIN patients compared to cancer-free smokers as evident by elevated odds ratios that ranged from 1.6 to 8.9. The gene methylation panel showed lung cancer prediction accuracy of 82-86\% and with addition of clinical variables improved to $87-90 \%$. With sensitivity at $95 \%$, specificity increased from $25 \%$ to $54 \%$ comparing clinical variables alone to their inclusion with methylation. The addition of methylation biomarkers to clinical variables would reduce false positive screens by ruling out onethird of smokers eligible for CT screening and could increase cancer detection rates through expanding risk assessment criteria.

\section{INTRODUCTION}

Lung cancer (LC) remains the leading cause of cancer-related death for men and women in the US [1]. The success of CT screening in the National Lung
Screening trial (NLST) for reducing LC mortality led to the recommendation by The Centers for Medicare and Medicaid (CMS) to screen people ages 55 to 77 who have a minimum 30 pack-year smoking history and currently smoke or have quit within the past 15 years [2]. However, 
these eligibility criteria or similar criteria by NCCN only capture $40 \%$ of the incident LC cases [3, 4]. Screening is estimated to save more than 12,000 lives, but cost Medicare $\sim 2$ billion dollars, annually $[5,6]$. This is due in part to the high false positive rate of $\mathrm{CT}$ screening as evident by the $39 \%$ of NLST participants that had at least one positive screening result (detection of indeterminate nodule) with $>96 \%$ of those findings being classified as false positive [7].

The addition of molecular biomarkers interrogated in accessible biologic fluids such as sputum could provide better risk stratification to prioritize selection of smokers for CT screening and thereby substantially improve its predictive value and lower costs by reducing followup screens and biopsies [8,9]. Gene silencing through methylation of cytosine in $\mathrm{CpG}$ islands in conjunction with chromatin remodeling leads to the development of heterochromatin of the gene promoter region, which denies access to regulatory proteins needed for transcription [10]. This epigenetically driven process is a major and causal event silencing hundreds of genes involved in all aspects of normal cellular function during LC initiation and progression [10]. Others and we have shown that gene specific promoter hypermethylation detected in sputum provides an assessment of field cancerization within the lungs of smokers that in turn predicts LC [11-17]. Specifically, our group showed that detecting gene methylation in exfoliated cells could predict cancer up to 18 months prior to clinical diagnosis, and was independently validated through case-control studies for predicting LC risk [11, 12]. However, the incorporation of this validated methylation panel in sputum into existing risk assessment models has not been assessed in a population-based setting that could identify high-risk smokers who would benefit most from a CT screen. A major challenge in conducting a prospective study for predicting LC risk is the need for a large population of high-risk smokers to yield enough cases of LC to accurately define the performance of the methylation panel.

Our previous case-control study used prevalent Stage I LC patients compared to cancer-free smoker controls to validate gene methylation panels for predicting LC [12]. Prior findings support our hypothesis of an expanding field of precancerous changes throughout the aerodigestive tract demonstrated initially through histologic changes and subsequently by increasing frequencies of genetic and epigenetic changes detected in exfoliated cells as the cancer develops $[11,16,18]$. Thus, the increase in number of cancer-associated methylated genes, rather than a single gene, is used in risk prediction [12]. The current study addressed whether our validated gene methylation panel could be extended to improve the existing risk prediction model used to recommend people for a CT screen. To accomplish this goal we used three cohorts of people: ECOG-ACRIN5597 trial participants who had a confirmed Stage I diagnosis of LC (based on pathology following surgical resection), the Lovelace Smokers Cohort ([LSC], current and former smokers at high risk for LC), and the PLuSS Smokers cohort (also current and former smokers at high risk for LC). The ECOG-ACRIN5597 participants were recruited from within the U.S. and Canada to participate in a prevention trial using L-selenomethione [19]. Patients had undergone surgical resection prior to trial enrollment and baseline sputum was obtained prior to randomization to the placebo or intervention group. Gene methylation in sputum reflects lung field cancerization that remains in lung cancer patients post-resection [20]. We hypothesized that because our gene methylation test is based on detecting the field of injury in the lung and not the actual small tumor present, the ECOG-ACRIN5597 trial participants would still have extensive field cancerization and serve in our study as people who should receive a CT screen, while the smokers selected were all cancer-free at time of sputum collection. We initially evaluated the utility of the eight gene panel to classify risk for LC by comparing gene methylation prevalence at baseline in the ECOG-ACRIN5597 patients who met the Medicare guidelines to receive a CT screen to screen eligible subjects from two cancer-free smoker cohorts (LSC and PLuSS) described previously [21]. In addition, the performance of our methylation panel was assessed in all ECOG-ACRIN5597 patients who provided baseline sputum compared to LSC or PLuSS current or former smokers irrespective of meeting eligibility for receiving a $\mathrm{CT}$ screen.

\section{RESULTS}

\section{Study population}

The characteristics of the entire study populations are shown in Table 1 . As expected the ECOG-ACRIN LC cases were slightly older and more had quit smoking. Pack years were available for 259 LC cases and were comparable to current and former smokers in the PLuSS cohort, but significantly greater than the LSC cohort.

\section{Gene methylation in sputum as a classifier for lung cancer risk in CT screen eligible smokers}

The utility of the eight gene panel to classify risk for LC was evaluated by comparing gene methylation prevalence at baseline in the 371 ECOG-ACRIN5597 patients who met the Medicare guidelines to receive a CT screen to screen eligible subjects from two cancerfree smoker cohorts (LSC $[\mathrm{n}=466]$ and PLuSS $[\mathrm{n}=597])$ described previously [21].Comparative characteristics of "screen eligible" subjects are detailed in Table 2. Two analyses were performed to evaluate prediction accuracy for LC by comparing ECOG-ACRIN5597 and LSC versus 
Table 1: Characteristics of study populations

\begin{tabular}{lcccc}
\hline Variable & ECOG-ACRIN & LSC & PLuSS & P value \\
\hline $\mathrm{N}$ & 487 & 1380 & 718 & $<0.0001^{2}$ \\
Age (mean \pm SD) & $66.4 \pm 8.8$ & $57.0 \pm 9.6$ & $64.6 \pm 5.1$ & $234(33)$ \\
Sex (male, \%) & $268(55)$ & $339(25)$ & & $<0.0001$ \\
Smoking status & & & $424(59)$ & $<0.0001$ \\
$\quad$ Current & $160(33)$ & $756(55)$ & $294(41)$ & \\
$\quad$ Former & $327(67)$ & $624(45)$ & $55 \pm 21$ & $<0.0001^{2}$ \\
Pack-years ${ }^{1}$ (mean \pm SD) & $56 \pm 37$ & $41 \pm 20$ & \\
\hline
\end{tabular}

${ }^{1}$ Pack-years were available for 259 of the ECOG-ACRIN patients.

${ }^{2}$ Comparing ECOG-ACRIN to LSC. P values are calculated using $\chi^{2}$ for binary or categorical variables and one-way ANOVA for continuous variables.

ECOG-ACRIN5597 and PLuSS cohort. The prevalence for methylation of all genes was significantly increased in the ECOG-ACRIN patients compared to cancer-free smokers as evident by elevated odds ratios that ranged from 1.6 to 8.9 (Table 3). ROC curves comparing the eight-gene methylation panel for ECOG-ACRIN5597 to LSC or PLuSS showed classification accuracy of $82 \%$ and $86 \%$ (Figure 1A, 1B). ROC curves restricted to the subset of ECOG-ACRIN5597 subjects $(n=194)$ with pack years available were identical to those in Figure 1 (classification accuracies of $89 \%$ and $91 \%$, respectively). Most important, the gene panel when added to the clinical variables increased the prediction accuracy from $76 \%$ to $87 \%\left(\mathrm{p}=7.2 \times 10^{-9}\right.$ for delta area under the curve [AUC] $)$ and $74 \%$ to $90 \%\left(\mathrm{p}=3.2 \times 10^{-16}\right.$ for delta AUC) when ECOG-ACRIN5597 subjects were compared to LSC or PLuSS, respectively (Figure 1, Table 4 ).

Random sampling to match for the difference in distributions of age, sex, and smoking status between ECOG-ACRIN5597 and LSC/PLuSS had no effect on prediction accuracy of the gene panel (Table 4, Supplementary Figure 1). With the sensitivity set at $95 \%$, the addition of the methylation biomarkers increased specificity from $25 \%$ (clinical variables only) to $54 \%$, while NPV and PPV were increased from $88 \%$ to $94 \%$ and $47 \%$ to $58 \%$, respectively (average values comparing ECOG-ACRIN5597 versus LSC/PLuSS; Table 4).
A

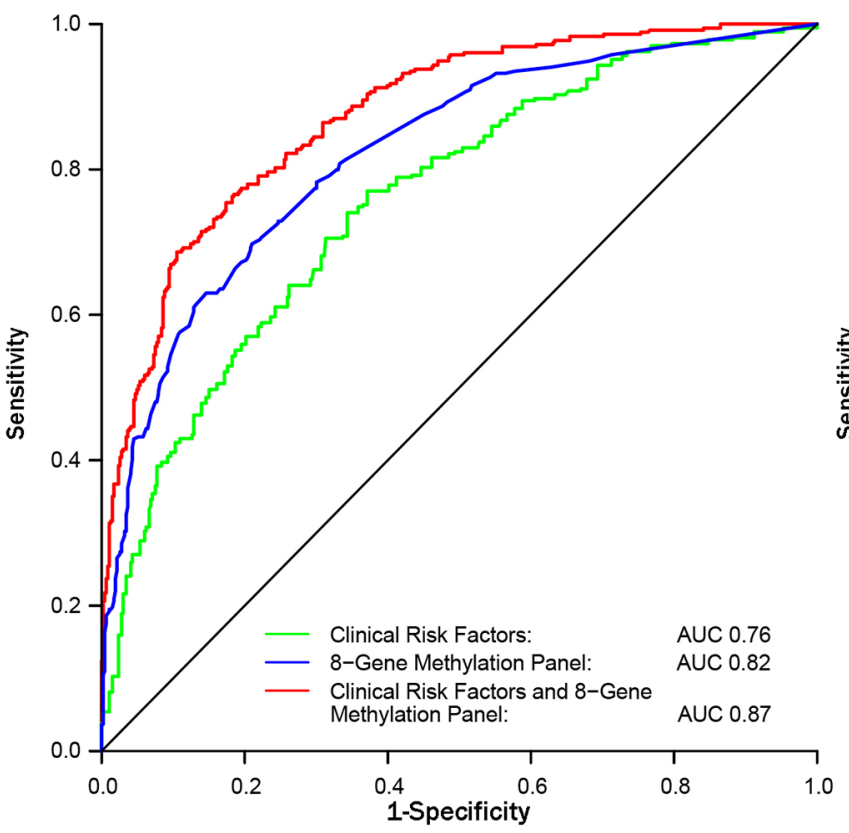

B ECOG and PLUSS

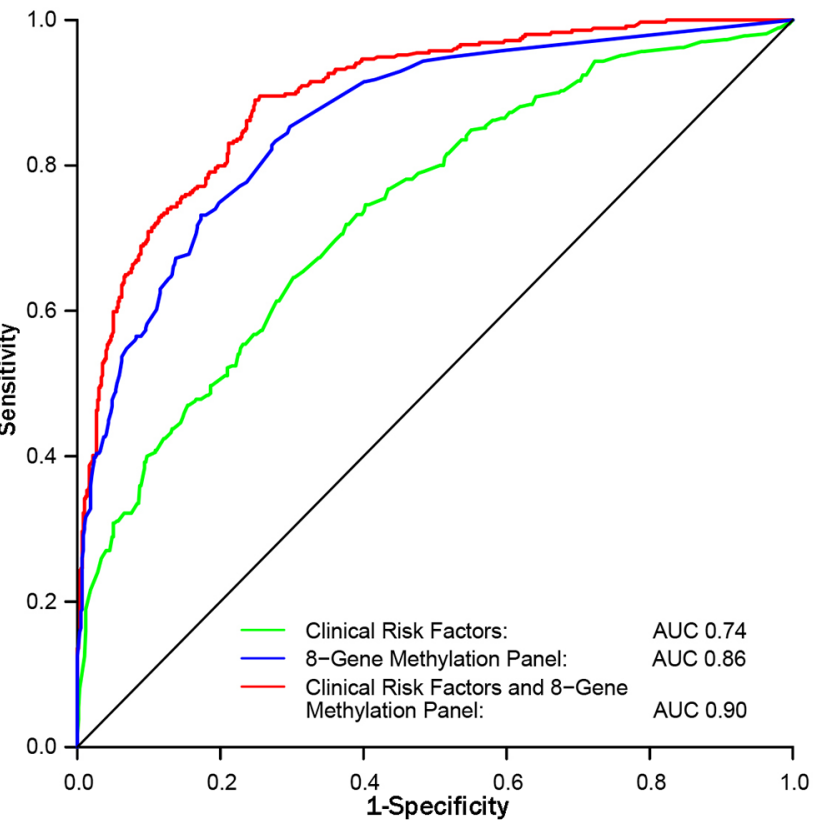

Figure 1: ROC curves for comparing the sensitivity and specificity for the eight-gene methylation panel with and without clinical risk factors between ECOG-ACRIN and LSC (A) or PLuSS (B) for classifying lung cancer risk. 
Table 2: Comparative demographics between ECOG-ACRIN, LSC, and PLuSS cohort members eligible for CT screening

\begin{tabular}{lcccc}
\hline Variable & ECOG-ACRIN & LSC & PLuSS & P value \\
\hline $\mathrm{N}$ & 371 & 466 & 597 & \\
Age (mean $\pm \mathrm{SD})$ & $67 \pm 5.9$ & $63.5 \pm 5.7$ & $64.4 \pm 4.5$ & $<0.0001$ \\
Sex (male, \%) & $210(57)$ & $119(26)$ & $210(35)$ & $<0.0001$ \\
Smoking status & & & & $<0.0001$ \\
$\quad$ Current & $119(32)$ & $277(59)$ & $390(65)$ & \\
$\quad$ Former & $252(68)$ & $189(41)$ & $207(35)$ & \\
Pack-years ${ }^{1}($ mean $\pm S D)$ & $67 \pm 30$ & $56 \pm 24$ & $59 \pm 19$ & \\
\hline
\end{tabular}

${ }^{1}$ Pack-years were available for 194 of the ECOG-ACRIN patients.

$P$ values are calculated using $\chi^{2}$ for binary or categorical variables and one-way ANOVA for continuous variables.

\section{Gene methylation classifier extends lung cancer risk assessment beyond medicare screening guidelines}

The performance of the gene methylation panel was also evaluated in the ECOG-ACRIN versus LSC or PLuSS cohorts independent of their age, smoking history and smoking status (years quit), albeit everyone was 40 years and older and had smoked a minimum of 10 pack years. This design increased the samples sizes to 487,1380 , and 718 for the ECOG-ACRIN, LSC, and PLuSS cohorts, respectively. ROC curves comparing the eight-gene methylation panel for ECOG-ACRIN5597 to LSC or PLuSS each showed classification accuracy of $88 \%$ when combining clinical risk factors with the 8-gene methylation panel. Accordingly, this relaxed inclusion criteria also did not significantly diminish specificity when sensitivity was set at $95 \%$.

\section{DISCUSSION}

This large cross sectional study of smokers provides compelling support that a significant increase in classification accuracy and accompanied specificity for predicting LC risk can be achieved by addition of a gene methylation panel in sputum to the inclusion variables for CT screening when comparing these cancer patients to two geographically distinct cancer-free smoker cohorts. Moreover, classification accuracy of the methylation panel was similar when relaxing the Medicare inclusion criteria for CT to include all ECOG-ACRIN cases that smoked compared to all cancer-free subjects from LSC and PLuSS. A limitation of these studies was that our assessment was restricted to the $\sim 70 \%$ of smokers who produce sputum. However, with the advent of the Lung Flute, most individuals that do not spontaneously produce sputum will be able to provide a specimen for risk assessment [22]. Thus, implementation of this gene methylation panel for population-based screening could be a paradigm shift for LC management by providing a much improved risk assessment model that will save more lives through increased number of screen-detected cancer, while greatly reducing the number of false screens through exclusion of lower risk smokers.

The retrospective nature of this study design allowed us to define the classification accuracy of the biomarker panel in a sample size of cases $(n=487)$ that was comparable to that detected by the NLST screening trial of 53,439 smokers [7]. Importantly, using participants from the ECOG-ACRIN5597 trial also addressed for the first time the generalizability of a gene methylation biomarker panel for risk assessment through studying LC cases from across the U.S. and Canada with comparison to two geographically distinct cohorts of smokers. Another major distinguishing feature of our study beyond sample size from other sputum-based risk assessment publications is the continued reproducibility regarding the performance of genes within this biomarker panel across five independent studies [11, 12, 23-25]. This outcome likely results from the fact that the genes studied are not methylated in normal cells of any lineage thereby being cancer-specific and the use of the nested, MSP assay that has a reproducible sensitivity of 1 methylated allele in 20,000 unmethylated alleles to allow interrogation of sputum, a heterogeneous mixture of cells where the epithelial fraction is often less than 3\% [11]. Moreover, high specificity is maintained in the stage 2 PCR for detecting methylated alleles through the use of annealing temperatures that exceed the melting point of the primers and short denaturation and extension cycles (15-20 sec; [11]). Finally, the fact that high classification accuracy was achieved through comparison of sputum from resected LC cases to controls strongly substantiates that the expanding field of injury with concomitant methylation is the major feature distinguishing cases from controls.

While our studies with a validated gene methylation panel in sputum have improved classification accuracy for LC in screen-eligible smokers as evident by an increase in 
Table 3: Comparison of gene promoter methylation prevalence in sputum from ECOG-ACRIN lung cancer patients to the lovelace smokers cohort (LSC) and pittsburgh PLuSS cohort

\begin{tabular}{|c|c|c|c|c|c|}
\hline Gene & $\begin{array}{c}\text { ECOG-ACRIN } \\
(\mathrm{n}=371)^{1}\end{array}$ & $\operatorname{LSC}(n=466)^{1}$ & PLuSS $(n=597)^{1}$ & $\begin{array}{l}\text { OR }^{2}(95 \% \text { CI) } \\
\text { (ECOG/LSC) }\end{array}$ & $\begin{array}{c}\mathrm{OR}^{2}(95 \% \mathrm{CI}) \\
\text { (ECOG/PLuSS) }\end{array}$ \\
\hline P16 & $132(36)$ & $92(20)$ & $89(15)$ & $2.3(1.6-3.2)$ & $3.2(2.3-4.5)$ \\
\hline$M G M T$ & $152(42)$ & $125(26)$ & $140(23)$ & $2.0(1.5-2.8)$ & $2.4(1.8-3.2)$ \\
\hline$D A P K$ & $157(43)$ & 87 (19) & $77(13)$ & $3.3(2.3-4.6)$ & $5.0(3.6-7.1)$ \\
\hline RASSF $1 A$ & $37(10)$ & $2(0.4)$ & 0 & $7.4(1.8-31.4)$ & $\mathrm{NC}$ \\
\hline GATA4 & $265(73)$ & $174(37)$ & $198(33)$ & $3.9(2.8-5.3)$ & $4.9(3.6-6.6)$ \\
\hline GATA5 & $164(45)$ & $62(13)$ & $55(9)$ & $5.3(3.6-7.6)$ & $7.9(5.5-11.5)$ \\
\hline$P A X 5 a$ & $116(32)$ & $87(19)$ & $68(11)$ & $1.6(1.2-2.3)$ & $3.2(2.2-4.5)$ \\
\hline$P A X 5 \beta$ & $117(32)$ & $33(7)$ & $30(5)$ & $6.2(4.0-9.8)$ & $8.9(4.7-14.1)$ \\
\hline
\end{tabular}

$\mathrm{NC}$, not able to calculate. ${ }^{1}$ Number in parenthesis under columns of ECOG-ACRIN, LSC, and PLuSS is prevalence of gene methylation. ${ }^{2}$ Adjustment for age, sex, and smoking status was included in logistic regression. Cohort identifier was coded as two dummy variables with ECOG-ACRIN set as the reference.

Table 4: Performance of gene methylation as a classifier for lung cancer risk

\begin{tabular}{lcccccc}
\hline & AUC (95\% CI) & Pvalue $^{1}$ & Sensitivity $^{2}$ & Specificity & PPV (\%) & NPV (\%) \\
\hline ECOG-ACRIN vs. LSC & & & & & & \\
Clinical risk factors & $0.76(0.73-0.79)$ & & 95 & 29 & 51 & 88 \\
Methylation panel & $0.82(0.79-0.85)$ & 0.0018 & 95 & 31 & 51 & 89 \\
Clinical + methylation & $0.87(0.85-0.90)$ & $7.2 \times 10^{-9}$ & 95 & 52 & 60 & 93 \\
ECOG-ACRIN vs. PLuSS & & & & & & \\
Clinical risk factors & $0.74(0.71-0.79)$ & & 95 & 24 & 44 & 89 \\
Methylation panel & $0.86(0.84-0.89)$ & $1.2 \times 10^{-9}$ & 95 & 47 & 52 & 94 \\
Clinical + methylation & $0.90(0.88-0.92)$ & $3.2 \times 10^{-16}$ & 95 & 56 & 56 & 94 \\
\hline
\end{tabular}

${ }^{1} \mathrm{P}$ value for delta AUC with model containing clinical risk factors only as the reference. ${ }^{2}$ Sensitivity set to $95 \%$.

specificity from $24 \%$ to $56 \%$ with sensitivity set at $95 \%$, adding other methylated genes to our panel is unlikely to yield significant improvement due to the correlation among genes for differentiating case status [12]. Rather, independent sets of biomarkers that can be used in conjunction with this gene methylation panel are needed to significantly extend specificity. Changes in circulating metabolites that can be quantitated are emerging as sensitive readouts for many diseases and a plasma metabolome signature, because of its dimensionality resulting from genetic and epigenetic changes driving the expansion of field cancerization in the smoker's lung, could extend our prediction model beyond methylation biomarkers [26-31]. While this approach remains untested, promising recent metabolomic profiling studies of moderate sample size are identifying discriminatory metabolites with LC classification accuracy of $77-88 \%$ $[32,33]$.
The ultimate translation of this work should be to provide primary care and/or pulmonary physicians with the option of ordering a low cost $(\leq \$ 200)$ insurance reimbursable validated LC risk assessment test to guide decision making regarding receiving a $\mathrm{CT}$ scan. Our model to date significantly improves classification accuracy beyond the current Medicare guideline, will allow expanding the number of smokers considered for screening, and should better define eligibility for receiving a CT scan by removing smokers with a low probability for LC based on the addition of methylation to the risk assessment. Our patented technology [34] is amenable to a CLIA setting through development of robotic/liquid handling for sputum processing, DNA isolation, bisulfite modification, and assembling of the Stage I and II MSP reactions in a 96-well format in conjunction with low cost SYBR-Green based detection of methylated products using real-time PCR. 


\section{METHODS}

\section{Subject recruitment and biospecimen collection}

Study participants were resected LC patients from a prevention trial and subjects from two geographically distinct cancer free smoker cohorts. Eligibility criteria for participation in the prevention trial included the following: age $\geq 18$ years; 6 to 36 months from complete resection of histologically proven stage IA (pT1N0) or stage IB (pT2N0) non-small cell LC (carcinoid tumors were excluded [19]). The institutional review board for human studies approved the protocols and written consent was obtained from subjects. Following consent onto the correlative study, the Lovelace study coordinator sent a collection kit to the study site. Sputum was collected at time of entry onto study. Sputum was collected from $85 \%$ of ECOG-ACRIN patients within 18 months post-surgery.

Each participant was asked to provide two consecutive spontaneous sputum samples collected at home at each time point as described previously [11]. Study participants placed the sputum cups in a postagepaid mailer addressed to the study coordinator at Lovelace. Material from the second 3-day pooled sputum was used for this study. The collection of two sputum samples at each time point was based on the finding by Kennedy et al. [35] that the second sample has a higher success rate $(80 \%)$ in producing an adequate sputum sample based on established cytologic standards, attributed to a 'learning effect' in adequate sputum collection. Following receipt, the sputum samples were pelleted and washed in Saccomanno's fixative. A small portion was smeared onto two or three slides and stained with Papanicoleau prior to cytologic diagnosis with the remaining sample stored at $-80^{\circ} \mathrm{C}$ until time for DNA isolation. Sputum containing epithelial cells from the upper or lower airways has proven satisfactory for methylation assays and using these criteria, virtually $100 \%$ of samples were adequate for study [11].

Two cancer-free cohorts, the LSC and Pittsburgh PLuSS Cohort (PLuSS), were used to validate the classification accuracy of the gene methylation panel for predicting LC risk $[21,36]$. These participants were cancer-free and methylation was assessed in sputum collected at cohort enrollment.

\section{DNA isolation and methylation specific PCR}

Sputum DNA was isolated using methods previously described with yields of DNA that ranged from 5-100 $\mu \mathrm{g}[11,12]$. The eight genes selected were based on positive performance in our initial nested, casecontrol study in a Colorado cohort [11]. These genes included P16, MGMT, DAPK, RASSF1A, GATA4, GATA5, PAX $5 \alpha$ and PAX5 $\beta$. These genes are cancer specific genes methylated solely in epithelial cells. DNA was bisulfite modified and two-stage, nested methylation specific polymerase chain reaction (MSP) assays were used for increased sensitivity for detection of promoter methylation in sputum and plasma as described [11]. Methylation was scored as positive or negative based on the detection of a visible band in the gel. The immense cellular heterogeneity in sputum, where the epithelial fraction is typically $<3 \%$ of the specimen, limits the ability to quantitate methylation, thus methylation was scored as positive or negative.

\section{Statistical analysis}

The association between methylation of each gene measured in sputum collected at baseline and risk for LC using ever smokers enrolled in LSC $(\mathrm{n}=466)$, PLuSS $(\mathrm{n}=597)$, and ECOG-ACRIN5597 $(\mathrm{n}=371)$ was assessed using logistic regression. Study subjects were restricted to those who met the Medicare screening criteria with exception of pack years that was available for 194 of the 371 ECOG-ACRIN subjects [2]. Area under the curve (AUC) of a receiver operating characteristic (ROC) curve was calculated to assess the prediction performance of the logistic regressions with different sets of covariates. The basic model included age (as a continuous variable), sex, and smoking status (as a binary variable) that represent risk factors for $\mathrm{LC}$ available from all groups. Methylation status of each gene was defined as methylated or unmethylated based on the gel image with respect to detecting a methylated PCR product. The methylation status of the eight genes as eight independent variables was included in the basic model to evaluate the delta change in AUC. The methylation index approach showed prediction performance that was inferior to using the methylation status of each individual gene in the model (not shown). This may be due to the fact that individual gene methylation is low to moderately correlated between each other and their likely difference in magnitude with respect to driving lung cancer development does not support using equal weight as done with the methylation index. Estimates of sensitivity, specificity, negative and positive predictive value (NPV, PPV) were calculated. Analyses were expanded to assess AUC and ROC using all ECOGACRIN subjects $(n=487)$ compared to LSC $(n=1380)$ or PLuSS $(\mathrm{n}=718)$ who had provided baseline sputum for methylation interrogation, irrespective of meeting Medicare screening criteria. All statistical analyses used two-sided tests and were conducted using SAS 9.3 and R 3.1.

\section{Abbreviations}

LC: lung cancer, NLST: National Lung Screening trial, CMS: The Centers for Medicare and Medicaid, LSC: Lovelace Smokers Cohort, PLuSS: Pittsburgh PLuSS Cohort, AUC: area under the curve, ROC: receiver operator characteristic, NPV: negative predictive value, PPV: positive predictive value. 


\section{ACKNOWLEDGMENTS}

This work was primarily supported by National Cancer Institute grant R01 CA095568 (SAB). The State of New Mexico as a direct appropriation from the Tobacco Settlement Fund to SAB through collaboration with University of New Mexico provided initial support to establish the LSC. R01CA097356 (SAB) and NIH/NCI P30 CA118100 provided additional support. The PLuSS cohort was established and supported through the NCI SPORE in Lung Cancer grant P50 CA090440 to the University of Pittsburgh (J.M.S.). This study was also supported in part by the ECOGACRIN Cancer Research Group (Robert L. Comis, MD and Mitchell D. Schnall, MD, PhD, Group Chairs Co-Chairs) by Public Health Service Grants CA180794, CA180820, CA180864, CA180844, CA180858, CA189828 and the National Cancer Institute, National Institutes of Health and the Department of Health and Human Services.

\section{CONFLICTS OF INTEREST} interests

The authors declare no competing financial

\section{REFERENCES}

1. Siegel R, Ma J, Zou Z, Jemal A. Cancer statistics, 2014. CA Cancer J Clin. 2014; 64:9-29.

2. Centers for Medicare \& Medicaid Services. Decision memo for screening for lung cancer with low dose computed tomography (LDCT) (CAG-00439N). 2015.

3. Wood DE, Kazerooni E, Baum SL, Dransfield MT, Eapen GA, Ettinger DS, Hou L, Jackman DM, Klippenstein D, Kumar R, Lackner RP, Leard LE, Leung AN, et al. Lung cancer screening, version 1.2015: featured updates to the NCCN guidelines. J Natl Compr Canc Netw. 2015; 13:2334; quiz 34.

4. Yang P, Wang Y, Wampfler JA, Xie D, Stoddard SM, She J, Midthun DE. Trends in subpopulations at high risk for lung cancer. J Thorac Oncol. 2016; 11:194-202.

5. Roxanne Nelson. CT lung cancer screening would cost medicare \$9 billion. Medscape. 2015.

6. Roth JA, Sullivan SD, Goulart BH, Ravelo A, Sanderson JC, Ramsey SD. Projected clinical, resource use, and fiscal impacts of implementing low-dose computed tomography lung cancer screening in medicare. J Oncol Pract. 2015; $11: 267-272$

7. National Lung Screening Trial Research Team, Aberle DR, Adams AM, Berg CD, Black WC, Clapp JD, Fagerstrom RM, Gareen IF, Gatsonis C, Marcus PM, Sicks JD. Reduced lung-cancer mortality with low-dose computed tomographic screening. N Engl J Med. 2011; 365:395-409.
8. Ludwig JA, Weinstein JN. Biomarkers in cancer staging, prognosis and treatment selection. Nat Rev Cancer. 2005; 5:845-856.

9. Belinsky SA. Gene-promoter hypermethylation as a biomarker in lung cancer. Nat Rev Cancer. 2004; 4:707-717.

10. Belinsky SA. Unmasking the lung cancer epigenome. Annu Rev Physiol. 2015; 77:453-474.

11. Belinsky SA, Liechty KC, Gentry FD, Wolf HJ, Rogers J, Vu K, Haney J, Kennedy TC, Hirsch FR, Miller Y, Franklin WA, Herman JG, Baylin SB, et al. Promoter hypermethylation of multiple genes in sputum precedes lung cancer incidence in a high-risk cohort. Cancer Res. 2006; 66:3338-3344.

12. Leng S, Do K, Yingling CM, Picchi MA, Wolf HJ, Kennedy TC, Feser WJ, Baron AE, Franklin WA, Brock MV, Herman JG, Baylin SB, Byers T, et al. Defining a gene promoter methylation signature in sputum for lung cancer risk assessment. Clin Cancer Res. 2012; 18:3387-3395.

13. Konno S, Morishita Y, Fukasawa M, Shu Y, Wang D, Tanaka R, Minami Y, Iijima T, Noguchi M. Anthracotic index and DNA methylation status of sputum contents can be used for identifying the population at risk of lung carcinoma. Cancer. 2004; 102:348-354.

14. Olaussen KA, Soria JC, Park YW, Kim HJ, Kim SH, Ro JY, Andre F, Jang SJ. Assessing abnormal gene promoter methylation in paraffin-embedded sputum from patients with NSCLC. Eur J Cancer. 2005; 41:2112-2119.

15. Wang YC, Hsu HS, Chen TP, Chen JT. Molecular diagnostic markers for lung cancer in sputum and plasma. Ann N Y Acad Sci. 2006; 1075:179-184.

16. Hsu HS, Chen TP, Wen CK, Hung CH, Chen CY, Chen JT, Wang YC. Multiple genetic and epigenetic biomarkers for lung cancer detection in cytologically negative sputum and a nested case-control study for risk assessment. J Pathol. 2007; 213:412-419.

17. Hubers AJ, Brinkman P, Boksem RJ, Rhodius RJ, Witte BI, Zwinderman AH, Heideman DA, Duin S, Koning R, Steenbergen RD, Snijders PJ, Smit EF, Sterk PJ, Thunnissen E. Combined sputum hypermethylation and eNose analysis for lung cancer diagnosis. J Clin Pathol. 2014; 67:707-711.

18. Auerbach O, Hammond EC, Garfinkel L. Changes in bronchial epithelium in relation to cigarette smoking, 19551960 vs. 1970-1977. N Engl J Med. 1979; 300:381-385.

19. Karp DD, Lee SJ, Keller SM, Wright GS, Aisner S, Belinsky SA, Johnson DH, Johnston MR, Goodman G, Clamon G, Okawara G, Marks R, Frechette E, et al. Randomized, double-blind, placebo-controlled, phase III chemoprevention trial of selenium supplementation in patients with resected stage I non-small-cell lung cancer: ECOG 5597. J Clin Oncol. 2013; 31:4179-4187.

20. Merrick DT, Gao D, Miller YE, Keith RL, Baron AE, Feser W, Kennedy TC, Blatchford PJ, Braudrick S, Hirsch FR, Heasley L, Bunn PA Jr, Franklin WA. Persistence of 
bronchial dysplasia is associated with development of invasive squamous cell carcinoma. Cancer Prev Res (Phila). 2016; 9:96-104.

21. Leng S, Liu Y, Weissfeld JL, Thomas CL, Han Y, Picchi MA, Edlund CK, Willink RP, Gaither Davis AL, Do KC, Nukui T, Zhang X, Burki EA, et al. 15q12 variants, sputum gene promoter hypermethylation, and lung cancer risk: a GWAS in smokers. J Nat Cancer Inst. 2015; 107(5).

22. Anjuman N, Li N, Guarnera M, Stass SA, Jiang F. Evaluation of lung flute in sputum samples for molecular analysis of lung cancer. Clin Transl Med. 2013; 2:15.

23. Belinsky SA, Nikula KJ, Palmisano WA, Michels R, Saccomanno G, Gabrielson E, Baylin SB, Herman JG. Aberrant methylation of p16(INK4a) is an early event in lung cancer and a potential biomarker for early diagnosis. Proc Nat Acad Sci U S A. 1998; 95:11891-11896.

24. Palmisano WA, Divine KK, Saccomanno G, Gilliland FD, Baylin SB, Herman JG, Belinsky SA. Predicting lung cancer by detecting aberrant promoter methylation in sputum. Cancer Res. 2000; 60:5954-5958.

25. Hubers AJ, Heideman DA, Duin S, Witte BI, de Koning HJ, Groen HJ, Prinsen CF, Bolijn AS, Wouters M, van der Meer SE, Steenbergen RD, Snijders PJ, Uyterlinde A, et al. DNA hypermethylation analysis in sputum of asymptomatic subjects at risk for lung cancer participating in the NELSON trial: argument for maximum screening interval of 2 years. $\mathrm{J}$ Clin Pathol. 2017; 70:250-254.

26. Braakhuis BJ, Tabor MP, Kummer JA, Leemans CR, Brakenhoff RH. A genetic explanation of Slaughter's concept of field cancerization: evidence and clinical implications. Cancer Res. 2003; 63:1727-1730.

27. Licchesi JD, Westra WH, Hooker CM, Herman JG. Promoter hypermethylation of hallmark cancer genes in atypical adenomatous hyperplasia of the lung. Clin Cancer Res. 2008; 14:2570-2578.

28. Belinsky SA, Palmisano WA, Gilliland FD, Crooks LA, Divine KK, Winters SA, Grimes MJ, Harms HJ, Tellez CS, Smith TM, Moots PP, Lechner JF, Stidley CA, Crowell RE. Aberrant promoter methylation in bronchial epithelium and sputum from current and former smokers. Cancer Res. 2002; 62:2370-2377.
29. Ooi AT, Gower AC, Zhang KX, Vick JL, Hong L, Nagao B, Wallace WD, Elashoff DA, Walser TC, Dubinett SM, Pellegrini M, Lenburg ME, Spira A, P Gomperts BN. Molecular profiling of premalignant lesions in lung squamous cell carcinomas identifies mechanisms involved in stepwise carcinogenesis. Cancer Prev Res (Phila). 2014; 7:487-495.

30. Jakubek Y, Lang W, Vattathil S, Garcia M, Xu L, Huang L, Yoo SY, Shen L, Lu W, Chow CW, Weber Z, Davies G, Huang J, et al. Genomic landscape established by allelic imbalance in the cancerization field of a normal appearing airway. Cancer Res. 2016; 76:3676-3683.

31. Nakachi I, Rice JL, Coldren CD, Edwards MG, Stearman RS, Glidewell SC, Varella-Garcia M, Franklin WA, Keith RL, Lewis MT, Gao B, Merrick DT, Miller YE, Geraci MW. Application of SNP microarrays to the genome-wide analysis of chromosomal instability in premalignant airway lesions. Cancer Prev Res (Phila). 2014; 7:255-265.

32. Puchades-Carrasco L, Jantus-Lewintre E, Perez-Rambla C, Garcia-Garcia F, Lucas R, Calabuig S, Blasco A, Dopazo J, Camps C, Pineda-Lucena A. Serum metabolomic profiling facilitates the non-invasive identification of metabolic biomarkers associated with the onset and progression of non-small cell lung cancer. Oncotarget. 2016; 7:1290412916. doi: 10.18632/oncotarget. 7354.

33. Mazzone PJ, Wang XF, Beukemann M, Zhang Q, Seeley M, Mohney R, Holt T, Pappan KL. Metabolite profiles of the serum of patients with non-small cell carcinoma. J Thorac Oncol. 2016; 11:72-78.

34. Belinsky S. Gene methylation as a biomarker in sputum. US Patent 9512 483. 2016.

35. Kennedy TC, Proudfoot SP, Piantadosi S, Wu L, Saccomanno G, Petty TL, Tockman MS. Efficacy of two sputum collection techniques in patients with air flow obstruction. Acta Cytol. 1999; 43:630-636.

36. Wilson DO, Weissfeld JL, Fuhrman CR, Fisher SN, Balogh P, Landreneau RJ, Luketich JD, Siegfried JM. The Pittsburgh Lung Screening Study (PLuSS): outcomes within 3 years of a first computed tomography scan. Am J Respir Crit Care Med. 2008; 178:956-961. 